\title{
Multiple alignment comparison of the non-structural genes of three strains of equine influenza viruses ( $\mathrm{H} 3 \mathrm{~N} 8$ ) isolated in Morocco
}

\author{
Mohamed Boukharta ${ }^{1 \dagger}$, Souad Azlmat ${ }^{2 \dagger}$, Mehdi Elharrak $^{3}$ and My Mustapha Ennaji ${ }^{*}$
}

\begin{abstract}
Background: Three equine influenza viruses, A/equine/Nador/1/1997(H3N8), A/equine/Essaouira/2/2004(H3N8), and A/equine/Essaouira/3/2004(H3N8), were isolated from different Equidae during local respiratory disease outbreaks in Morocco in 1997 and 2004. Their non-structural (NS) genes were amplified and sequenced.

Results: The results show high homology of NS nucleotide sequences of A/equine/Nador/1/1997 with European strains (i.e., A/equine/newmarket/2/93 and A/equine/Grobois/1/1998) and clustered into the European lineage. However, NS gene of A/equine/Essaouira/2/2004(H3N8) and A/equine/Essaouira/3/2004(H3N8) strains indicated high homology with equine influenza strains that had circulated before 1990 (A/equine/Fontainbleu/1/1979(H3N8), which belonged to a pre-divergent phase Amino acid sequence comparison of the NS1 protein with reference strain A/ equine/Miami/1963(H3N8) shows that the A/equine/Nador/1/1997(H3N8) strain has 12 substitutions at the residues $\mathrm{D} / 24 / \mathrm{N}, \mathrm{R} / 44 / \mathrm{K}, \mathrm{S} / 48 / \mathrm{I}, \mathrm{R} / 67 / \mathrm{Q}, \mathrm{A} / 86 / \mathrm{N}, \mathrm{E} / 139 / \mathrm{K}, \mathrm{A} / 112 / \mathrm{T}, \mathrm{E} / 186 / \mathrm{K}, \mathrm{L} / 185 / \mathrm{F}, \mathrm{A} / 223 / \mathrm{E}, \mathrm{S} / 213 / \mathrm{T}$ and S/228/P. In both $\mathrm{A} /$ equine/Essaouira/2/2004(H3N8) and A/equine/Essaouira/3/2004(H3N8) strains, the NS1 sequences present one common mutation at the residue: S/228/P.
\end{abstract}

Conclusion: It seems that all of these substitutions are not produced at the key residues of the RNA-binding domain (RBD) and the effector domain (ED). Consequently, we can suppose that they will not affect the potency of inhibition of cellular defences, and the virulence of the Moroccan equine strains will be maintained.

Keywords: Equine influenza virus, Non-structural protein (NS), RNA-binding domain, Effector domain

\section{Background}

Equine influenza virus is a highly contagious agent, capable of causing explosive outbreaks of respiratory disease among susceptible horse populations in many countries [1]. Two distinct subtypes of influenza virus, H7N7 (prototype influenza A/equine/Prague/1/56) and H3N8 (prototype influenza A/equine/Miami/1/63), have been recognized in the horse $[2,3]$. The first subtype (H7N7) is believed to be extinct and has not been isolated in the horse since 1979. The other subtype (H3N8) was isolated

\footnotetext{
*Correspondence: m.ennaji@yahoo.fr

${ }^{\dagger}$ Mohamed Boukharta and Souad Azlmat contributed equally to this work

1 Laboratory of Virology, Microbiology and Quality/ETB, Faculty

of Sciences and Techniques, Mohammedia, University Hassan

II Mohammedia-Casablanca, PO BOX 146, Quartier Yasmina,

Mohammedia 20650, Morocco

Full list of author information is available at the end of the article
}

for the first time in 1963 and was responsible for all recent equine influenza outbreaks $[4,5]$. These viruses belong to the Orthomyxoviridae family type A. The genome comprises eight segments of RNA [6]. These segments are encapsulated by a nucleoprotein (NP), which gives a helical symmetry to each. Six segments encode one protein: hemagglutinin (HA), neuraminidase (NA), nucleoprotein (NP), and three polymerases: PA, PB1, and PB2. Each of the other segments encodes two proteins: the matrix (M1 and M2) and a non-structural protein (NS1) and NS2 (NEP: nuclear export). The genomes of several virulent strains encode an 11th protein PB1-F2 [7]. NS1, NS2, and $\mathrm{PB} 1-\mathrm{F} 2$ proteins participate in viral replication and are not incorporated into the viral structure.

The presence of double-stranded RNA (dsRNA) is a signal of a viral infection, causing the activation of the 
cellular defence system through the synthesis of the interferon protein (IFN) [8]. However, influenza viruses have developed a strategy to antagonize the cellular defences. The non-structural protein NS1 is regarded as the major antagonist of the immune response of the host cells [9]. In most viruses, the NS1 protein consists of 230 amino acids (aa) and the NEP protein of 121 aa [10]. However, a size variability of the NS1 protein was observed, especially in the human and swine viruses [11]. In the case of H3N8 equine influenza virus, truncations have been shown as well as other influenza viruses $[12,13]$.

The linear structure of the NS1 protein contains two domains linked by a non-structured region composed of ten amino-acids: The first one is the RNA-binding domain (RBD), representing the $\mathrm{N}$-terminal protein (amino acids 1-73), the second is an effector domain (ED), which represents $\mathrm{C}$-terminal protein (amino acids 74-230) [14].

The RNA-binding domain has an alpha-helical structure and forms a symmetrical homo-dimer with a unique six-helical chain fold. The effector domain forms a dimer, and each monomer consists of seven beta-strands and three alpha helices [15]. The non-structural protein NS1 contains several interaction domains: the region of binding to dsRNA (residues 1-73), the specific cleavage and polyadenylation specific factor region (CPSF) (residues 175-210), the region of the binding protein (PABP) II (poly (A)-binding protein-II) (residues 218-225), the region of nuclear localization signal 1 (NLS 1) (residues 34-38), the region nuclear localization signal 2 (NLS 2: nuclear localization signal) (residues 211-216), the region of the nuclear export signal (NES) (residues 132-141), and the region that interacts with subunit regulatory $\mathrm{p} 85-\beta$ of phosphatidylinositol 3-kinase (PI3K) (residues 89-93, 137-142 and 164-167) [16].

The PDZ domain binding is present at the C-terminal of NS1 among equine influenza viruses (H3N8) (sequence ESEV/EPEV), and it is known as a determinant of viral virulence.

In the present study, we report analysis of the partial nucleotide sequence of the NS gene and the NS1 protein for three Moroccan equine influenza viruses: A/Equine/ Nador/1/97, A/Equine/Essaouira/2/2004, and A/Equine/ Essaouira/3/2004, and their genetic comparison with influenza strains (human, equine, swine, avian) available in the GenBank database.

\section{Methods}

\section{Viruses}

A/equine/Nador/1/97 was isolated in Nador from a mule after four passages on eleven -day-old embryonated specific pathogen-free chicken eggs (ECE4) as described by Kissi et al. (1998) [17]. Both A/equine/Essaouira/2/2004 and $\mathrm{A} /$ equine/Essaouira/3/2004 were isolated respectively from an infected donkey and a horse during 2004 outbreaks in Essaouira. The isolates were passaged on Madin Darby Canine Kidney cell line after two passages (MDCK2) at $34{ }^{\circ} \mathrm{C}$ in an atmosphere of $5 \% \mathrm{CO}_{2}$ in Eagle's minimum essential media supplemented with $5 \%$ foetal calf serum.

\section{Viral RNA extraction and amplification}

Viral RNA was extracted directly from isolates using a PureLink Viral RNA/DNA Mini-Kit (Invitrogen, Van Allen Way, Carlsbad, California, USA) following the manufacturer's recommended protocol. Complementary DNA was obtained by RT reactions, which were carried out by using a SuperScript III First-Strand Synthesis System (Life Technologies, Carlsbad, CA, USA).

PCR was performed using a Platinum PCR SuperMix High-Fidelity Kit (Invitrogen, Carlsbad, CA, USA) with cDNA obtained using primers specific for NS1F (ATGGATTCCAACACTGTGTC) and NS1R (TCAAACTTCTG $(A / G) C T C A A T T G)$ at a final concentration of $0.5 \mu \mathrm{M}$ for primers. Primer design is detailed by Tissier (2008) [18] and was synthesized by the Unité d'Appui Technique à la Recherche Scientifique, Centre National de Recherche Scientifique et Technique (CNRST), Rabat, Morocco. The assay was performed on the SmartCycler instrument (Cepheid, Sunnyvale, CA, USA), using the following thermocycling protocol: incubation at $95{ }^{\circ} \mathrm{C}$ for $2 \mathrm{~min}$, then 35 cycles of denaturation at $95{ }^{\circ} \mathrm{C}$ for $30 \mathrm{~s}, 52{ }^{\circ} \mathrm{C}$ for $1 \mathrm{~min}$ for hybridization, and $72{ }^{\circ} \mathrm{C}$ for $30 \mathrm{~s}$, and a final extension for $3 \mathrm{~min}$ at $72{ }^{\circ} \mathrm{C}$.

\section{Sequencing NS Genes and phylogenetic Analysis}

The amplified PCR NS products were sequenced. Briefly, the PCR products were purified using EXOSAPIT (USB Corporation, Cleveland, OH, USA) and bidirectionally sequenced by using BigDye1 Terminator v3.1 (Applied Biosystems, Foster City, Calif. USA) on a 3130xl model sequencer (Applied Biosystems). Analysis of the electro-phoregramm was carried out with the sequencing analysis software version 5.3.1 (Applied Biosystems). We performed phylogenetic analysis of 54 influenza strains (including equine, avian and human isolates) published in GenBank database, selected using the neighbour-joining method with bootstrap analyses of 500 replicates in CLUSTAL W. The tree was visualized using MEGA5.1 software (http://megasoftware. net/) [19].

\section{Determination of amino acid sequences of NS genes}

Multiple alignments of the deduced amino acid sequences were used by Basic Local Alignment Search Tool (BLAST) software. Comparing NS1 protein of 
(See figure on next page.)

Fig. 1 Phylogenetic analysis of the partial nucleotide sequences of NS of 54 strains (human, avian, swine and equine). A/Aichi/2/1968(H3N2), M34829; A/Alaska/6/1977(H3N2), K01332; A/AnnArbor/6/1960(H2N2), M23968; A/Beijing/32/1992(H3N2), D30667; A/Berkeley/1/1968(H2N2), M12590; A/Canterbury/02/2005(H3N2), CY007807; A/FortWarren/1/1950(H1N1), K00576; A/Houston/18515/1984(H1N1), M12594; A/ Houston/24269/1985(H3N2), M17699; A/Kitakyushu/159/93(H3N2), D30676; A/Leningrad/134/17/1957(H2N2), M81578; A/Maryland/2/1980(H1N1), M12595; A/NewYork/191/2005(H3N2), CY006127; A/USSR/90/1977(H1N1), K00578; A/Adorn/8/1972(H3N2), V01102; A/chicken/Germany/ N/1949(H10N7), AF001407; A/duck/Alberta/60/1976(H12N5), J02105; A/eq/LaPlata/93(H3N8), AF001673; A/equine/Avesta/1/1993(H3N8), AB543512; A/equine/Detroit/3/1964(H7N7), M80970; A/equine/Essaouira/2/2004(H3N8), JQ955611; A/equine/Essaouira/3/2004(H3N8), JQ955614; A/equine/Fontainbleu/1/1979(H3N8), CY032409; A/equine/Grobois/1/1998(H3N8), AY328471; A/equine/Italy/1062/1991(H3N8), CY032377; A/equine/Jilin/1/1989(H3N8), M65020; A/equine/Miami/1/1963(H3N8), CY028840; A/equine/Nador/1/1997(H3N8), JX182368; A/ equine/Newmarket/2/1993(H3N8), FJ375211; A/equine/Ohio/1/2003(H3N8), DQ124186; A/equine/Prague/1/1956(H7N7), M80944; A/equine/ Richmond/2/2007(H3N8), FJ195442; A/equine/Rome/5/1991(H3N8), AF001669; A/equine/Uruguay/1/1963(H3N8), CY032425; A/equine/ Yvelines/2136/1989(H3N8), AF001666; A/goose/Guangdong/3/1997(H5N1), AY028445; A/gull/Maryland/19/1977(H2N9), CY005810; A/gull/ Maryland/704/1977(H13N6), M80959; A/gull/Massachusetts/26/1980(H13N6), U96744; A/gull/Minnesota/945/1980(H13N6), U96738; A/laughing gull/Delaware Bay/2838/1987(H13N2), CY005068; A/mallard/New York/6750/1978(H2N2), M80945; A/mallard/NewYork/6874/1978(H3N2), M25375; A/mallard/Wisconsin/428/1975(H5N1), U85380; A/pintail/Alberta/119/1979(H4N6), M25374; A/ruddy turnstone/New Jersey/47/1985(H4N6), M80946; A/swine/1976/1931(H1N1), M55482; A/swine/Hokkaido/2/1981(H1N1), M80961; A/swine/lowa/15/1930(H1N1), M80965; A/swine/ Wisconsin/1/1961(H1N1), M80951; A/tern/Turkmen/18/1972(H3N3), M55466; A/turkey/Minnesota/10734/1995(H5N2), U85391; A/turkey/ Ontario/7732/1966(H5N9), U85376; A/turkey/Oregon/1971(H7N3), M16623. Numbers next to nodes indicate bootstrap value percentages (>90 \%)

Moroccan isolates to the reference strain (A/Equine/ Miami/1/1963), the amino acid substitutions that were involved in both RNA-binding domain (RBD) and effector domain (ED) were determined.

\section{Results and discussion}

Partial NS nucleotide sequences of the Moroccan equine influenza isolates (A/equine/Nador/1/1997, A/equine/ Essaouira/2/2004, and A/equine/Essaouira/3/2004) were submitted to the GenBank database, and their accession numbers of NS genes are JX182368, JQ955611, and JQ955614, respectively.

\section{BLAST results}

The BLAST result shows that the nucleotide sequences of the NS gene of two strains A/equine/Essaouira/2/2004 and A/equine/Essaouira/3/2004 presents high similarity between them, and towards other old strains like A/equine/Miami/1/1963 ( $>99 \%$ ), A/equine/Uruguay/1/63(99\%), A/eq/LaPlata/1/88 (>99\%), and A/ equine/Fontainebleau/79 (98\%). These strains have circulated before 1990. Since then, the equine influenza viruses have diverged into two antigenically distinct lineages, Eurasian and American. According to several authors, the pre-divergent strains have disappeared and were supplanted by viruses that evolved in lineages and sub-lineages [20].

The partial nucleotide sequence of the NS gene of A/ equine/Nador/1/97 strain is genetically distant towards the pre-divergent strains. Indeed, it demonstrates high homology to the strains that have circulated in Europe during the 1990s, i.e., A/equine/Newmarket/2/1993 (99 \%), A/equine/Avesta/1/1993 (99\%), A/equine/ Grobois/1/98 (98 \%), A/equine/Italy/1199/1992 (98 \%), and A/equine/Roma/5/1991 (98 \%).

\section{Phylogenetic analysis}

Data obtained from BLAST was confirmed by the phylogenetic analysis based on 54 nucleotide sequences of the NS gene of influenza A viruses, which were isolated from various species (human, avian, swine, and equine). The NS genes of the Moroccan strains are clustered into a lineage of the equine influenza virus (H3N8) that belongs to the A allele. The two strains, A/equine/ Essaouira/2/2004 and A/equine/Essaouira/3/2004, belong to the pre-divergent phase, while the A/equine/ Nador/1/97 belongs to the Eurasian lineage (Fig. 1). Moreover, the sequencing analysis of the HA (accession numbers JQ955607, JQ955609, and JQ955612) of A/ equine/Nador/1/1997, A/equine/Essaouira/2/2004, and A/equine/Essaouira/3/2004, respectively) revealed same data. Such results show that these three strains isolated in Morocco share the same ancestors as the equine influenza (H3N8) virus and that there was no genetic reassortment between co-circulating strains in Morocco [21].

The data matrix containing 54 taxa and phylogenetic analyses were deposited into TreeBase under accession url: http://purl.org/phylo/treebase/phylows/study/ TB2:S18066.

\section{Comparison analysis of amino acids alignment}

Compared to the reference strain A/equine/ Miami/1/1963, the sequences of amino acids of the NS1 protein of the strain $\mathrm{A} /$ equine/Nador/1/1997 have 12 substitutions: D/24/N, R/44/K, S/48/I, R/67/Q, A/86/V, E/139/K, A/112/T, E/186/K, L/185/F, A/223/E. S/213/T, and $\mathrm{S} / 228 / \mathrm{P}$. These mutations occurred in both RNAbinding and effector domains (Fig. 2).

The $\mathrm{D} / 24 / \mathrm{N}$ substitution occurred in a changing region of the RBD (19 to 28) of the NS1 protein of influenza viruses [22]. This mutation may not affect the structure of 


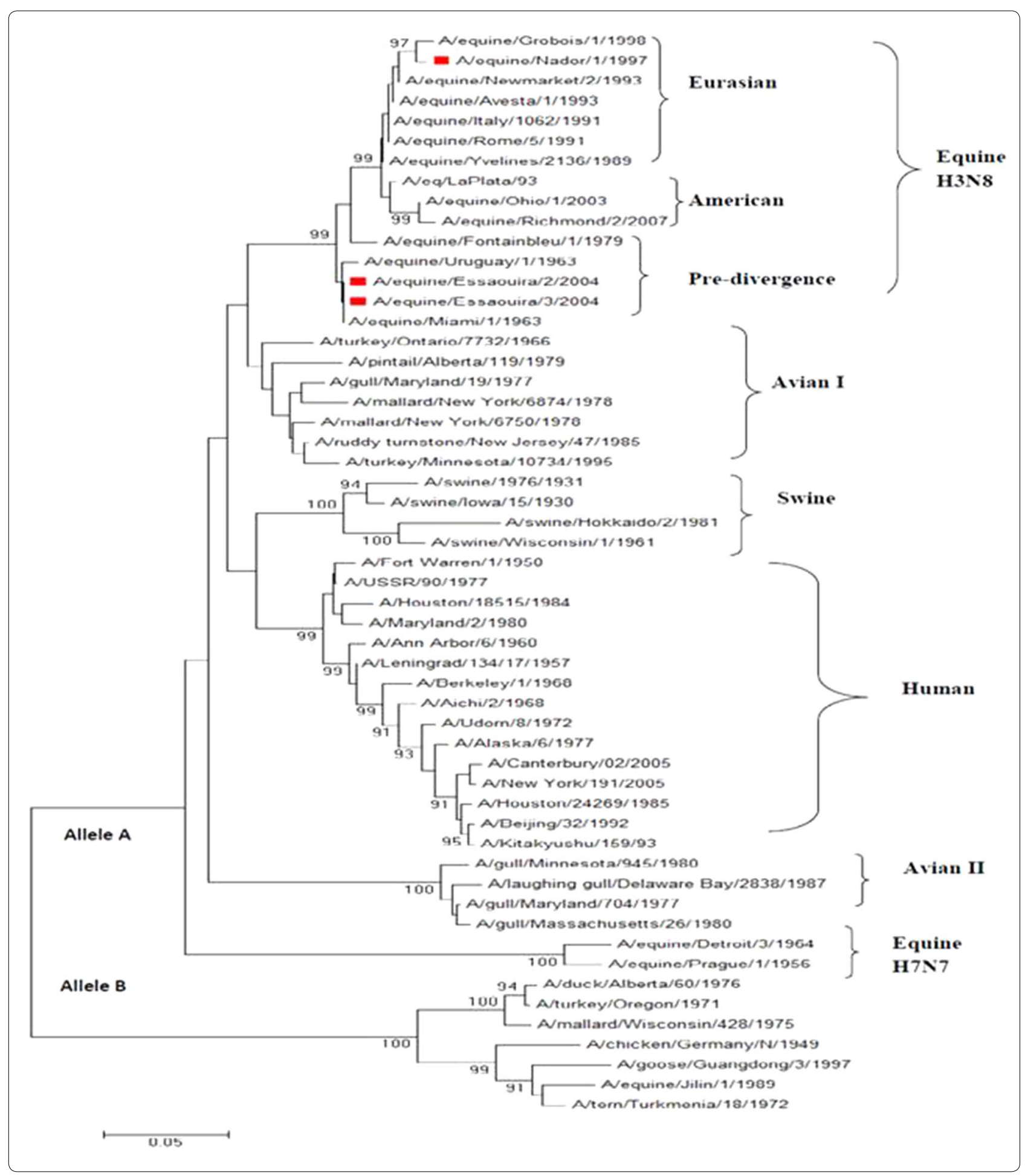




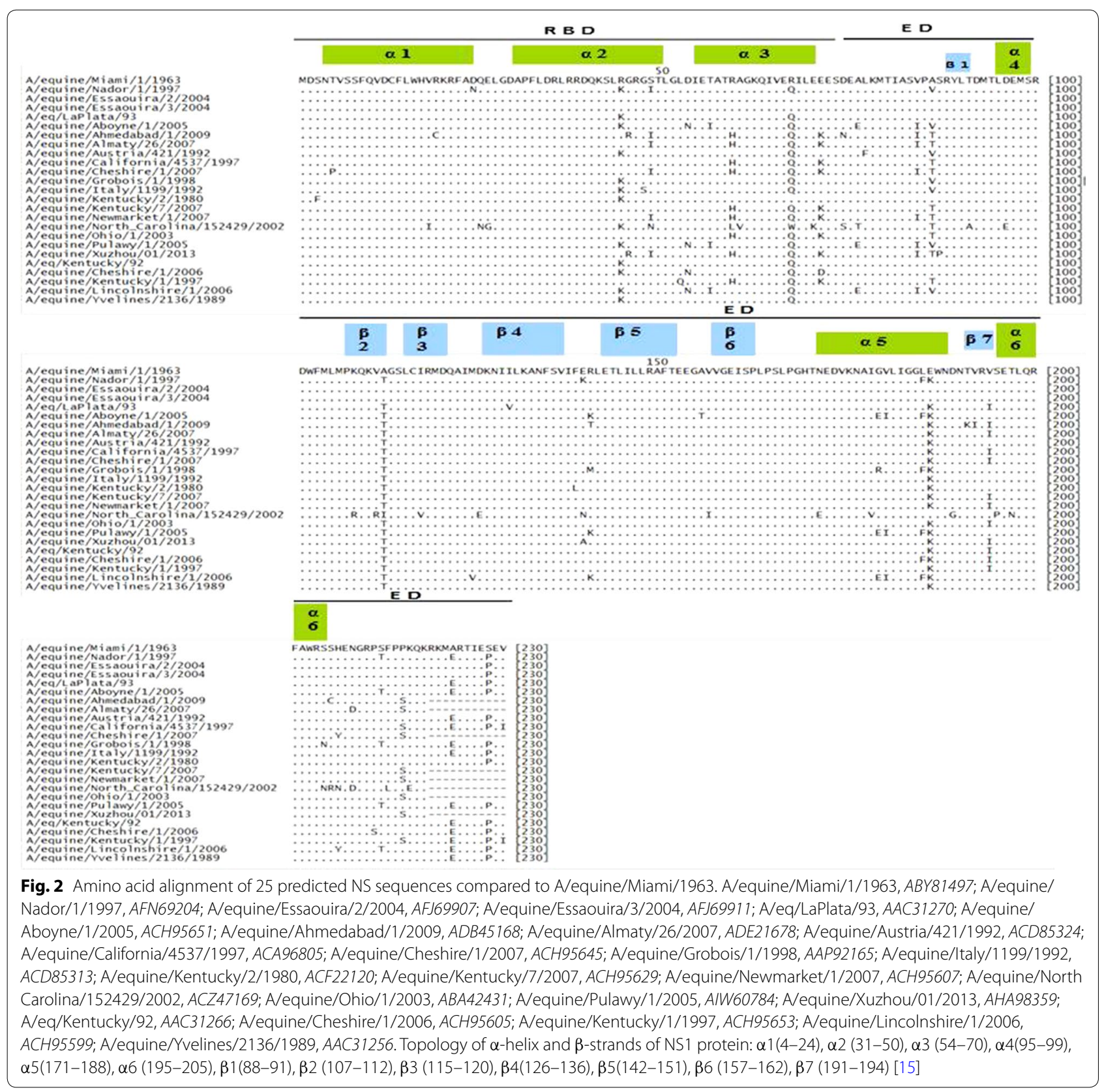

the NS1 protein RNA binding domain or its activity. This finding is confirmed by the virulence of the A/equine/ Nador/1/1997 strain, which caused severe respiratory signs among naturally infected mules. The same substitution was also reported by Parveen and Asad (2010) [23] concerning the human strain A/North Dakota/04/2009 (H1N1) (ACR67137).

The three mutations (R/44/K, S/48/I, and $\mathrm{R} / 67 / \mathrm{Q})$ revealed on the RBD do not seem to affect virulence, because they do not concern the following residues: Thr5, Pro-31, Asp-34, Arg-35, Arg-38, Lys-41, Gly-45, Arg-46, and Thr-49, which are closely linked to the activity of the NS1 protein. Several authors have reported that these nine amino acids are the key residues of RBD activity $[9,10,24]$.

Mutations that occurred on the effector domain were reported in several sites recognized as having functional roles. In fact, mutations at residues $\mathrm{A} / 86 / \mathrm{V}$ and $\mathrm{A} / 112 / \mathrm{T}$ occurred in a specific region of the eIF4GI protein (81 to 113), and they participate with the protein PABPI in the initiation of mRNA viral translation $[25,26]$.

The binding of the protein CPSF30 (cleavage and polyadenylation specific factor) inhibits the maturation of 


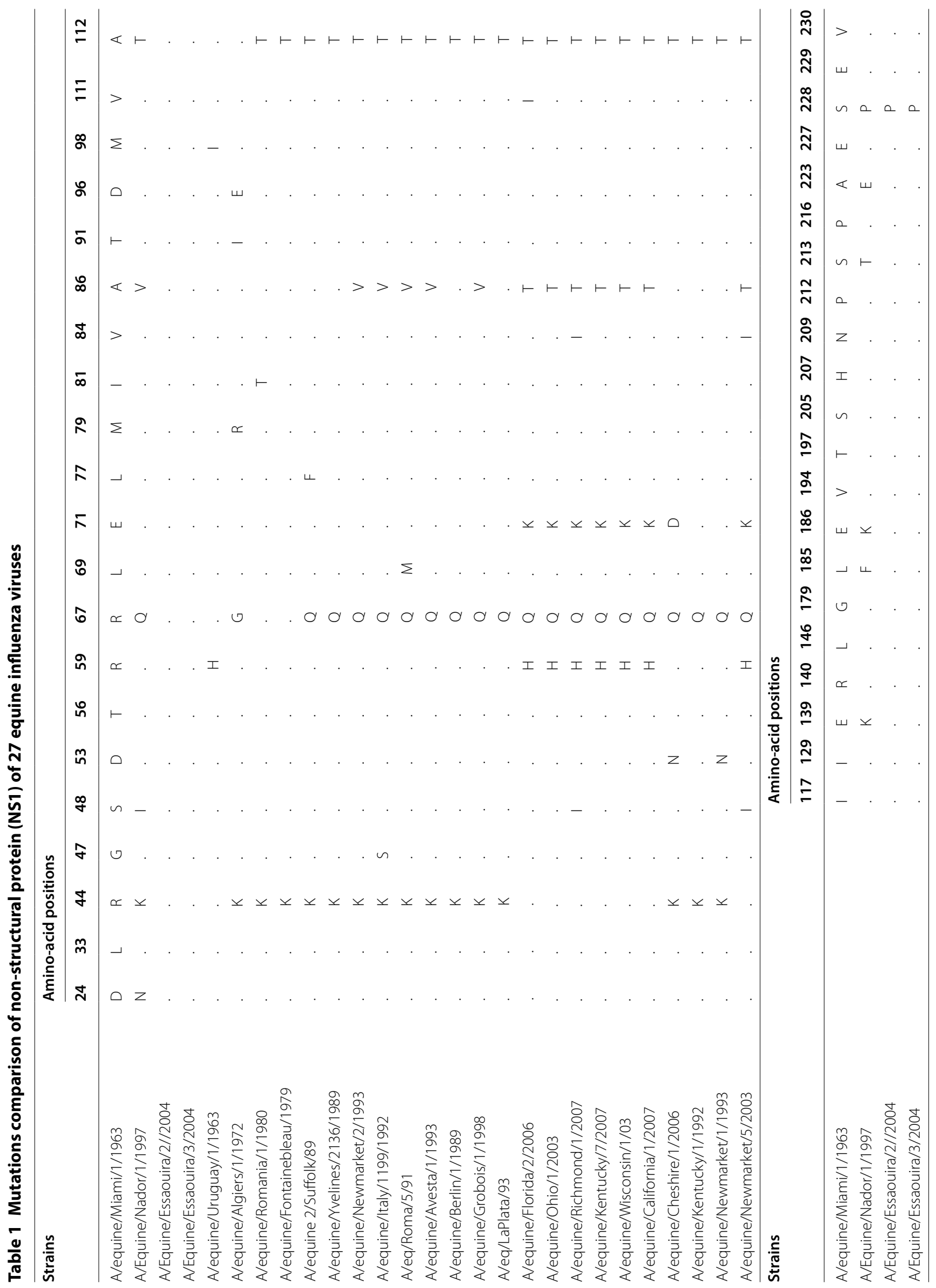




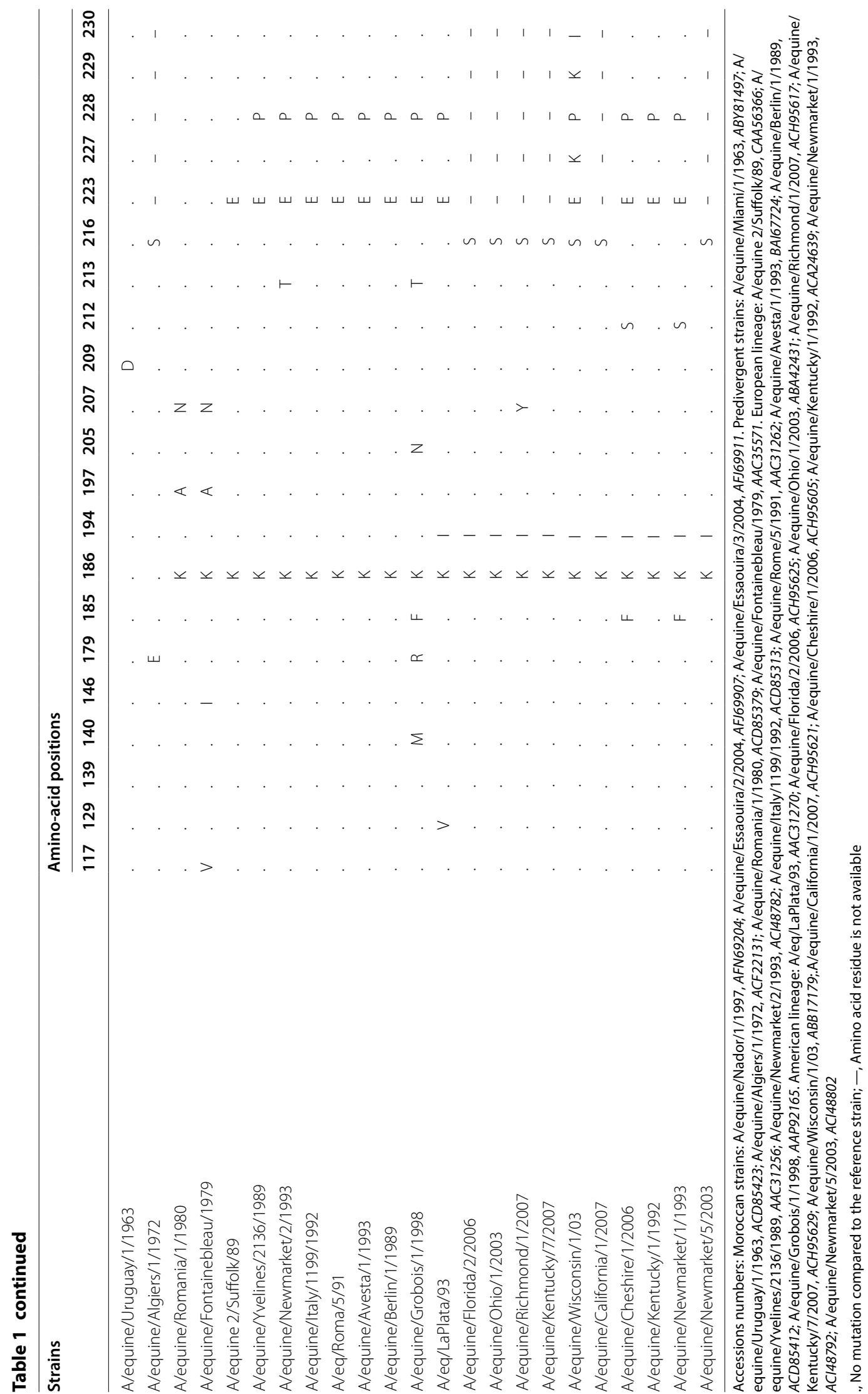


cellular pre-mRNA. This link is provided by amino acids 144, 184, and 188 (186 region) [15, 27]. It appears that both $\mathrm{L} / 185 / \mathrm{F}$ and $\mathrm{E} / 186 / \mathrm{K}$ mutations may not reduce the affinity of NS1 to CPSF30 protein, and consequently do not inhibit viral replication.

Three substitutions, E/139/K, S/213/T, and A/223/E, were reported in domain activity of nucleocytoplasmic distribution in the cell of the NS1 protein. The E/139/K mutation is located at the nuclear export signal region (NES: nuclear export signal) (residues 132-141) [16]. Furthermore, similar mutations at this residue were also observed for the NS1 of the following strains: N/139/E (A/equine/North Carolina/152429/2002, ACZ47169); and E/139/A (A/equine/Xuzhou/01/2013, AHA98359) (Fig. 2). The two mutations, $S / 213 / T$ and $A / 223 / E$, occurred at nuclear localization signal (NLS2) and PABPII domains, respectively. NLS2 is defined within the region between amino acids 213 and 221. This domain is present in the NS1 proteins of most influenza A virus strains. However, several substitutions affecting it were noticed, such as: S/213/T (i.e.,: A/equine/Nador/1/1997, AFN69204 and A/equine/Aboyne/1/2005, ACH95651), and $\mathrm{P} / 214 / \mathrm{S} \quad$ (i.e.,: A/equine/Cheshire/1/2007, ACH95645). However, nuclear localization signal 1 (NLS1) contains the stretch of basic amino acids AspArg-Leu-Arg-Arg (codons 34 to 38). This sequence is conserved in three Moroccan strains as all NS1 proteins of influenza A viruses [28]. It appears that the substitution occurred in NLS2 do not seem to interfere with the nuclear localization of NS1 protein; because the intracellular localization is regulated by one or two nuclear localization signals (NLS) and a nuclear export signal (NES) [29].

Multiple comparisons of the NS1 protein of 27 equine influenza viruses show that the mutations $\mathrm{D} / 24 / \mathrm{N}$ and $\mathrm{E} / 139 / \mathrm{K}$ characterize the A/equine/Nador/1/1997(H3N8) strain, while the $\mathrm{A} / 86 / \mathrm{V}$ and $\mathrm{S} / 213 / \mathrm{T}$ mutations are shared with several European lineage strains. However, the eight substitutions $(\mathrm{R} / 44 / \mathrm{K}, \mathrm{S} / 48 / \mathrm{I}, \mathrm{R} / 67 / \mathrm{Q}, \mathrm{A} / 112 / \mathrm{T}$, $\mathrm{E} / 186 / \mathrm{K}, \mathrm{L} / 185 / \mathrm{F}, \mathrm{A} / 223 / \mathrm{E}$, and $\mathrm{S} / 228 / \mathrm{P}$ ) are present in various equine influenza viruses (H3N8) belonging to different phases of evolution (pre-divergence and the American and European lineages) (Table 1).

The NS1 protein of both strains of Essaouira presents an identical sequence of them. Therefore, compared to reference strain A/equine/Miami/1/1963, the carboxyl terminus of the NS1 proteins shows a common mutations regarding substitution S/228/P. Moreover, the PDZ-binding sequence, Glu-Pro-Glu-Val (EPEV) motif appears in both avian as well as swine, human and equine viruses.

In addition, the presence of the EPEV sequence in the NS1 protein of three equine Moroccan strains is an indicator of virulence [30]. This sequence, present at the C-terminus of NS1 of the H5N1 virus (sequence ESEV/ EPEV) and the H1N1 pandemic of 1918 (sequence KSEV) but absent among seasonal human viruses, establishes binding with the PDZ domains [31]. The ESEV sequence is common among avian viruses. Its presence in NS1 of the A/equine/Miami/1/1963(H3N8) strain is related to its ancestral avian virus, which infected horses of North America in 1963 [32], while the S/228/P mutation observed in the three Moroccan strains is considered to be an adaptation of avian influenza viruses (H3N8) origin to the new equine host [33].

\section{Conclusion}

The study of NS1 sequences of three Moroccan strains shows that all mutations are not produced at the key residues of RBD (RNA-binding domain) and ED (effector domain) domains, and therefore do not appear to affect the potency of inhibition of cellular factor defences, and their virulence.

\section{Abbreviations}

BLAST: basic local alignment search tool; RT-PCR: reverse transcriptase-polymerase chain reaction; RBD: RNA-binding domain; ED: effector domain; NS: non-structural protein; NEP: nuclear export protein.

\section{Authors' contributions}

The work presented here was carried out in collaboration between all authors. BM participated in the design of the study, carried out the molecular genetic studies, analysis and interpretation of data, the sequence alignment phylogenetic and drafted the manuscript. SA participated equitably in the molecular genetic studies and interpretation of data. MME, EHM, are conceived of the study and helped revising the manuscript. All authors read and approved the final manuscript.

\section{Author details}

${ }^{1}$ Laboratory of Virology, Microbiology and Quality/ETB, Faculty of Sciences and Techniques, Mohammedia, University Hassan II Mohammedia-Casablanca, PO BOX 146, Quartier Yasmina, Mohammedia 20650, Morocco. ${ }^{2}$ Department of Biology, Instruction Military Hospital Med V Rabat, University Mohammed V Souissi, Rabat, Morocco. ${ }^{3}$ Society of Pharmaceutical and Veterinary Products, Virology Laboratory, Av Hassan II, BP 4569 Rabat, Morocco.

\section{Acknowledgements}

This study was supported by the University Hassan II, Mohammedia-Casablanca, Faculty of Sciences and Techniques, Mohammedia, Morocco. The authors thank the Inspection de Service de Santé Militaire/Division Vétérinaire staff for their support. Experimental and protocol designs were performed at the Laboratory of Virology, Microbiology and Quality/ETB (Faculty of Sciences and Technics, Mohammedia, University Hassan II Mohammadia-Casablanca). Strain isolations were performed at the Society of Pharmaceutical and Veterinary Products, Virology Laboratory, Rabat, Morocco. NS gene sequencing was done at Functional Genomics Platform, Technical Support Unit for Scientific Research, CNRST, and Rabat, Morocco.

\section{Compliance with ethical guidelines}

\section{Competing interests}

The authors declare that they have no competing interests.

Received: 24 February 2015 Accepted: 11 September 2015 Published online: 24 September 2015 


\section{References}

1. Myers C, Wilson D. Equine Influenza Virus. Clin Tech Equine Pract. 2006:5:187-96.

2. Sovinova O, Tumova B, Pouska F, Nemec J. Isolation of a virus causing respiratory disease in horses. Acta Virol. 1958;2:52-61.

3. Waddell GH, Teigland MB, Sigel MM. A new influenza virus associated with equine respiratory disease. J Am Vet Med Assoc. 1963;143:587-90.

4. Timoney PJ. Equine influenza. Comp. Immun MicrobioL infect Dis. 1996;19:205-11.

5. Barbic L, Madic J, Turk N, Daly J. Vaccine failure caused an outbreak of equine influenza in Croatia. Vet Microbiol. 2009;133:164-71.

6. Lai ACK, Rogers KM, Glaser A, Tudor L, Chambers T. Alternate circulation of recent equine-2 influenza viruses ( $\mathrm{H} 3 \mathrm{~N} 8$ ) from two distinct lineages in the United States. Virus Res. 2004;100:159-64.

7. Burnouf T, Griffiths E, Padilla A, Seddik S, Stephano MA, Gutierrez JM. Assessment of the viral safety of antivenoms fractionated from equine plasma. Biologicals. 2004;32:115-28.

8. Jiao P, Tian G, Li Y, Deng G, Jiang Y, Liu C, Liu W, Bu Z, Kawaoka Y, and Chen $\mathrm{H}$. A single-amino-acid substitution in the NS1 protein changes the pathogenicity of $\mathrm{H} 5 \mathrm{~N} 1$ avian influenza viruses in mice. J Virol. 2008;82:1146-54.

9. Hale BG, Randall RE, Ortin G, Jackson D. The multifunctional NS1 protein of influenza A viruses. J Gen Virol. 2008;89:2359-76.

10. Wang L, Suarez DL, Pantin-Jackwood M, Mibayashi M, García-Sastre A, Saif YM, Lee CW. Characterization of influenza virus variants with different sizes of the Non-structural (NS) genes and their potential as a live influenza vaccine in poultry. Vaccine. 2008;26:3580-6.

11. Suarez DL, Perdue ML. Multiple alignment comparison of the non-structural genes of influenza A viruses. Virus Res. 1998;54:59-69.

12. Quinlivan M, Zamarin D, Garci'a-Sastre A, Cullinane A, Chambers T, Palese P. Attenuation of equine influenza viruses through truncations of the NS1 protein. J Virol. 2005;79:8431-9.

13. Na W, Kang B, Kim HI, Hong M, Park SJ, Jeoung HY, An DJ, Moon H, Kim JK, Song D. Isolation and genetic characterization of naturally NStruncated H3N8 equine influenza virus in South Korea. Epidemiol Infect. 2014;142:759-66.

14. Dundon WG, Capua I. A Closer look at the NS1 of influenza virus. Viruses. 2009;1:1057-72.

15. Dongzi $L$, Jingfang $L$, Zhizhen $Z$. Structure and function of the NS1 protein of influenza A virus. Acta Biochim Biophys Sin. 2007;39:155-62.

16. Darapaneni V, Prabhaker VK, Kukol A. Large-scale analysis of influenza A virus sequences reveals potential drug target sites of non-structural proteins. J Gen Virol. 2009;90:2124-33.

17. Kissi B, Daoudi N, El kantour A, Id sisi yahia K, Benazzou H. First isolation in the Morocco of the equine influenza virus called A/Equi/Morocco/1/97. Esp. Vét 1998; 14-10.

18. Tissier O. Comparative study of sequences of the equine influenza virus isolated in French. Thesis submitted to the University Claude BernardLyon I (medicine-pharmacy) 2008. http://www2.vetagro-sup.fr/bib/ fondoc/th_sout/phpdrupal.php?annee=2008. Accessed 11 May 2015 .
19. Tamura K, Dudley J, Nei M, Kumar S. MEGA4: molecular evolutionary genetics analysis (MEGA) software version 4.0. Mol Biol Evol. 2007;24:1596-9.

20. Martella V, Elia G, Decaro N, Di Trani L, Lorusso E, Campolo M, et al. An outbreak of equine influenza virus in vaccinated horses in Italy is due to an $\mathrm{H} 3 \mathrm{~N} 8$ strain closely related to recent North American representatives of the Florida sub-lineage. Vet Microbiol. 2007;121:56-63.

21. Boukharta M, Touil N, El Fahim E, Terta M, Kissi B, Loutfi C, El Harrak M, Ennaji MM. Phylogenetic and molecular characterization of the equine influenza virus A (H3N8) causing the 1997 and 2004 outbreaks in Morocco. J Equine Vet Sci. 2013;34:942-8.

22. Suarez DL, Perdue ML. Multiple alignment comparison of the non-structural genes of influenza A viruses. Virus Res. 1998;54:59-69.

23. Parveen S, Asad UK. Structural and functional analysis of NS1 and NS2 proteins of H1N1 subtype. Genom Proteom Bioinform. 2010;8:190-9.

24. Yin C, Khan JA, Swapna GV, et al. Conserved surface features form the double-stranded RNA binding site of non-structural protein 1 (NS1) from influenza A and B viruses. J Biol Chem. 2007;282:20584-92.

25. Marc D. NS1 influenza viruses: an influential protein. Virologie. 2012;16:95-106.

26. Burgui I, Aragon T, Ortın J, Nieto A. PABP1 and elF4GI associate with influenza virus NS1 protein in viral mRNA translation initiation complexes. J Gen Virol. 2003;84:3263-74.

27. Zohari S, Gyarmati P, Ejdersund A, Berglöf U, Thorén P, Ehrenberg M, Czifra G, Belák S, Waldenström J, Olsen B, Berg M. Phylogenetic analysis of the non-structural (NS) gene of influenza A viruses isolated from mallards in Northern Europe in 2005. Virol J. 2008;5:147.

28. Greenspan D, Palese P, Krystal M. Two nuclear location signals in the influenza virus NS1 nonstructural protein. J Virol. 1988;62:3020-6.

29. Tynell J, Melén K, Julkunen I. Mutations within the conserved NS1 nuclear export signal lead to inhibition of influenza A virus replication. Virol J. 2014;11:1-12.

30. Tombari W, Nsiri J, Larbi I, Guerin JC, Ghram A. Genetic evolution of low pathogenecity H9N2 Avian influenza viruses in Tunisia: acquisition of new mutations. Virol J. 2011;8:1-12.

31. Munier S, Moisy D, Marc D, Naffakh N. Interspecies transmission, adaptation to humans and pathogenicity of animal influenza viruses. Pathol Biol (Paris). 2010;58:59-68.

32. Dea S, Elazhary MASY, Roy RS. The human and animals influenza virus. A review of the literature. Can Vet J. 1980;21:171-8.

33. Bogoyavlenskiy A, Berezin V, Prilipov A, Korotetskiy I, Zaitseva I, Kydyrmanov A, Karamedin K, Ishmukhametova N, Asanova S, Sayatov M, Zhumatov K. Phylogenetic analysis of the non-structural (NS) gene of influenza A viruses Isolated in Kazakhstan in 2002-2009. Virologica sinica. 2011;26:376-85

\section{Submit your next manuscript to BioMed Central and take full advantage of:}

- Convenient online submission

- Thorough peer review

- No space constraints or color figure charges

- Immediate publication on acceptance

- Inclusion in PubMed, CAS, Scopus and Google Scholar

- Research which is freely available for redistribution

Submit your manuscript at

www.biomedcentral.com/submit
C Biomed Central 